\title{
The Optimal Selective Logging Regime and the Faustmann Formula
}

\author{
Angels Xabadia and Renan U. Goetz * \\ University of Girona
}

November 13, 2008

\begin{abstract}
This study analyzes the optimal selective logging regime of a size-distributed forest where individual trees compete for scarce resources such as space, light, and nutrients. The decision problem of the forest manager is formulated as a distributed optimal control problem. The interpretation of the first-order conditions allows a generalization of the Faustmann formula. In an empirical part, this article numerically determines the optimal management regime of a size-structured forest and shows that the optimal selective logging regime is associated with a normal forest under a wider variety of situations than stated in the previous literature.
\end{abstract}

Key words: distributed optimal control; density effects; forest management; Faustmann rule; selective logging

JEL Classification: C610, C630, Q230

Corresponding author:

Renan Goetz, University of Girona

Departament of Economics

Campus de Montilivi, 17071 Girona, Spain

Tel: +34 972418719

Fax: +34 972418032

Email: renan.goetz@udg.edu

\footnotetext{
${ }^{*}$ We are grateful to Gustav Feichtinger, Kerry Smith, Vladimir Veliov, Tomislav Vukina and David Zilberman who provided comments on earlier drafts of this paper. This research has benefited from the financial support of the Generalitat de Catalunya (contract 2005SGR213), XREPP (Xarxa de referència d'R+D+I en Economia i Polítiques Públiques), and of the Ministry of Education and Science (contracts AGL2007-65548-C02-01/AGR and SUM2006-00019-C02).
} 


\section{$1 \quad 1$ Introduction}

2 Frequently, forest management is based on the Faustmann or maximum sustained yield rules, which deter-

3 mine the optimal cutting age of the trees. Since these criteria are based on the assumption that all trees have

4 the same age, their application leads to the clear cutting of the entire stand. This management regime has

5 been criticized because it pays no attention to the ecological value, in the form of biological diversity in for-

6 est land (Doyon et al., 2005; Sawadogo et al., 2005), and scenic or recreational values (Scarpa et al., 2000).

7 Since trees in a forest provide food, shelter and substrate for other life forms, maintaining a rich variety of

8 trees conserves biodiversity in a forest ecosystem (Lin and Buongiorno, 1998) and improves forest attributes

9 associated with scenic and recreational values of the forest land. For example, a complex tree and canopy

10 structure helps to provide preferable habitat for wildlife (Hunter, 1990; Whittam et al. 2002).

11 To overcome the negative effects of the clear cutting regime, tree selection silviculture (uneven-aged man-

12 agement), for which there is a very strong interest in temperate as well as in tropical regions, has been

proposed (Vanclay, 1995). Managers of public forests are likely to have a mandate to consider not only the monetary benefits to be obtained from timber production but also the benefits to be gained from biodiversity conservation, and from maintenance of forest land with high scenic and recreational values. In contrast, private landowners and timber companies might, a priori, be less interested in adopting a selective 
Several empirical studies have introduced the structuring variable diameter of the tree to resolve the problem of optimal management of the uneven-aged forest. Initially, Adams and Ek (1974) determined only the optimal long-run allocation of all trees among the different tree vintages, but not the optimal replacement periods. Haight et al. (1985) and Lin and Buongiorno (1998) solved simultaneously for the optimal long-run allocation of all trees among the different tree vintages, and the optimal replacement periods. These studies were formulated in a discrete framework, i. e., time and diameter can only take on certain values, and, consequently, they cannot provide an analytical formulation of the optimal selective logging rule. Although later studies by Adams et al. (1996), and Sedjo and Lyon (1990) utilized discrete time and a continuous structuring variable for their policy analysis, they did not establish an analytical formulation for the optimal logging pattern.

Moreover, several quite remarkable theoretical studies did provide a rule for the optimal selective logging regime by analyzing the properties of the transient path and of the steady state (Mitra and Wan, 1985; Mitra and Wan, 1986; Wan, 1994; Salo and Tahvonen, 2002; Uusivuori and Kuuluvainen, 2005; Cunha e Sa et al., 2007). However, these articles are based on a stylized analytical model where the growth process of the biomass is not modeled explicitly. Every year trees pass from the current to the sequent age class. As each age class is associated with a particular biomass that increases with age, trees "grow" as they get older. Hence, the current theoretical models do not establish a functional relationship between biomass and age, but rather form a tuple of different pairs of biomass and age. In this respect, their analytical results are limited to certain points of combinations of age and biomass, but do not fully describe the underlying biophysical processes proposed in the literature of biological mathematics (Keyfitz, 1968; Keyfitz, 1977).

The previous theoretical literature did not explicitly model competition between individuals belonging to the same population. Individuals compete for space or light and nutrients. In the absence of predators, the life cycle of a single individual is mainly influenced by the other individuals of the population. Thus, in order to model biological growth, mortality and reproduction processes correctly, one does not only have to take 
into account individual characteristics such as age but also the distribution of the individual characteristics

over the entire population. Given the same initial amount of biomass, the growth rate of the forest will be higher as more young individuals form part of it. In other words, the more young trees there are, the less competition individual trees face and therefore the growth rate of the entire forest increases with the share of young trees.

The reason why growth processes based on continuous time and a continuous structuring variable have not been considered may reside in the fact that they lead to distributed optimal control problems where the law of motion is given by partial differential equations (PDE), or partial integrodifferential equations ${ }^{1}$ if density effects are considered. The previous theoretical and empirical literature usually describes the evolution of an age (size) distributed forest by a set of difference equations in time for a number of age (size) cohorts. These difference equations are an approximation (discretization over time and age (cohorts)) of the continuous evolution of the forest over time and age. The previously employed discretization procedure seems reasonable and has been practiced widely; however, it is not known whether the set of difference equations describes the evolution correctly. The set of difference equations is set up ad hoc and is not derived from the underlying partial differential equation. Notice, for instance, that the set of difference equations in the paper by Haight (1987) is identical for an age and size structured population. However, the PDEs for age or size-structured populations are not identical. The PDE of a size-structure population incorporates a function that relates time and size and therefore is not present in the PDE for an age-structured population. ${ }^{2}$ On the other hand, partial differential or integrodifferential equations allow not only the age but also the size of the trees to be considered. In fact, the size of the trees determines their economic value. As discussed below, age can only be considered as a poor proxy for the size of a tree, and therefore, any analysis based on age instead of size may be misleading. Moreover, PDEs permit the price of timber to be formulated as a function of tree size, and to incorporate density effects. Consequently, considering competition between

\footnotetext{
${ }^{1}$ The unknown function of the PDE is a function of time and age (size). In cases where an integral over the unknown function forms part of a partial differential equation, the PDE becomes a partial integrodifferential equation.

${ }^{2}$ To be more precise this function is equal to one for an age-structured population since time and age move with the same speed.
} 
individuals, continuous time, and a continuous structuring variable allows the definition of an analytical formulation of the optimal harvesting rule for selective logging, and its comparison with the Faustmann rule, which is based on continuous time.

Unfortunately, if the forest dynamics are governed by a partial integrodifferential equation it is not possible to obtain a complete analytical solution of the optimal forest management regime and one has to resort to numerical techniques. In contrast to the existing literature where distributed control problems are solved numerically by a gradient projection method (Feichtinger et al., 2004) or Markov decision process models (Lin and Buongiorno, 1998), we employ a different technique known as the "Escalator Boxcar Train". This technique has the advantage of not requiring programming numerical algorithms since it can be implemented with standard optimization packages such as GAMS. Moreover, it simplifies the estimation of biological equations used in the model as it will be shown in the empirical study. A presentation of the numerical method used in this article can be found in Goetz et al. (2008).

This article presents a theoretical model that describes the characteristics of the optimal selective-logging regime of a size-distributed forest that maximizes timber net benefits. The law of motion of the economic model is governed by a partial integrodifferential equation that describes the evolution of the forest stock over time. This formulation allows size dependent economic variables and modeling biophysical processes to be taken into account more realistically. As an extension of the literature this article provides an analytical formulation of the optimal selective-logging rule whose interpretation allows generalization of the Faustmann formula. In an empirical part the article determines the optimal selective-logging regime of a size-distributed forest from a private perspective, and conducts a sensitivity analysis. It shows that the cyclical evolution of the variables vanishes along the optimal path giving rise to a non-cyclical logging pattern and a fairly uniform diameter distribution of the trees. This distribution provides a constant flow of income and is known as a normal forest. In comparison with the previous theoretical literature where a normal forest only emerged under special conditions, we find that the standard result is the emergence of a normal forest. 
The article is organized as follows. Section 2 describes the features of the model. As such it is divided into one subsection that describes the underlying biological processes and another that outlines the economic decision problem in the form of a distributed optimal control problem. Section 3 shows that the optimal selective cutting rule for a size-distributed forest can be interpreted as a generalization of the Faustmann formula for even-sized forests, and analyzes the implications of a steady-state on the optimal forest distribution.

The next section determines the optimal selective cutting regime in an empirical setting, and analyzes the changes in the long run outcome as a result of a change in different parameters. Finally, section 5 presents the conclusions.

\section{The model}

Before presenting the complete economic model that will allow us to determine the optimal selective logging regime, we have characterized the underlying biological model that describes the growth process of the trees.

\subsection{The growth process of the trees}

In previous theoretical economic literature the age of the tree is regarded as the structuring variable of the biological population (Salo and Tahvonen, 2002; Wan, 1994). In biological science, however, it is usually not the age but physiological or behavioral characteristics, for instance, size, life cycle stages, gender or genetic differences, or behavioral activities, that determine the biological life cycle of the individual (Cushing, 1988). Likewise, from an economic point of view it is not the age but the size of the tree that is important. The price of lumber changes with the size of the tree but not with age. And, as established by forest scientists, the age of a tree is not very closely related to its size (Björklund, 1999). Large genetic variety between the trees, and between the different local conditions of each tree makes it difficult to establish a functional relationship between size and age. Consequently, the age-size relationship resulting from an econometric estimation is very poor (Seymour and Kenefic, 1998). In forestry, the size of a tree, and 


$$
X(t)=\int_{l_{0}}^{l_{m}} x(t, l) d l .
$$

The forest dynamic is driven by the processes of reproduction, growth, and mortality, which in turn are influenced by environmental conditions. Let us define $g(E(t), l)$ the rate of change in the diameter of a tree, as a function of its current diameter $l$, where $E(t)$ presents a collection of environmental characteristics that affect the growth rate of the individual tree. In the absence of predators, these environmental characteristics are given by the local conditions where the tree is growing, and by the neighboring trees. The local conditions and the competition between individual trees for space, light, and nutrients affect the life cycle of each tree. Since our model does not consider space, the variable $E(t)$ presents exclusively the competition between individuals. ${ }^{3}$ Environmental characteristics $E(t)$ can be expressed by the total number of trees, or the basal area of the stand. A large basal area of the stand signifies a high competition pressure on the life cycle of an individual tree that decreases the diameter growth (Trasobares et al., 2004). Therefore, we use

\footnotetext{
${ }^{3}$ Although the literature on forest economics contains complex optimization models where space is considered explicitly, their solutions are based on heuristic approaches and not on efficient optimization techniques (Weintraub et al., 2007).
} 
the stand basal area to take account of the competition between individuals, ${ }^{4}$ that is,

$$
E(t)=\int_{l_{0}}^{l_{m}} \frac{\pi}{4} l^{2} x(t, l) d l .
$$

Hence, the change in the diameter over time of a single tree is given by

$$
\frac{d l}{d t}=g(E(t), l)
$$

The instantaneous death rate is denoted by $\delta(E(t), l)$. It describes the rate at which the probability of survival of a tree, given the environmental characteristics $E(t)$, decreases with time.

The reproduction of the forest can be modeled as internal reproduction or planting. In the former case we would obtain a boundary condition for the partial integrodifferential equation that reflects the reproduction process. Since seed production by individual trees is very high (Karlsson and Örlander, 2000), it is space, light, and nutrients that are the limiting factors for the upgrowth of young trees, and not the reproduction process itself. For this reason we can assume that the number of seeds that turn into seedlings is sufficiently large. This allows the forest manager to choose the number of trees with a diameter of $l_{0}$ by removing any additional trees. The number of upgrowing trees chosen is denoted by $p\left(t, l_{0}\right)$. In the case of planting, we are dealing with a forest that is completely managed, where young trees with a diameter of $l_{0}$ are planted and no biological reproduction takes place. Hence, for both reproduction systems the control variables for the management of the forest are given by $u(t, l)$ and $p\left(t, l_{0}\right)$, denoting cutting density at time $t$ with diameter $l$, and the flux of the trees with diameter $l_{0}$ respectively. Young trees are either grown up to diameter $l_{0}$, or planted with diameter $l_{0}$, at time $t$. Thus, the optimal forest management problem is a distributed optimal control problem where the time dependent control variable $u(t, l)$ is distributed over $l$ (Feichtinger and Hartl, 1986). In contrast, the time dependent boundary control variable $p\left(t, l_{0}\right)$ refers only to the initial

\footnotetext{
${ }^{4}$ We assume that the trees with different sizes are distributed evenly over the stand. If this is not the case, other intra-specific competition indices that are distance dependent, such as the Lorimer area index (García-Abril et al., 2007), are more appropriate.
} 


\footnotetext{
${ }^{5}$ If the structuring variable was age, the function $g$ would be constant and equal to 1 since the aging of the individual by one year corresponds to calendar time. In this case the term $\frac{\partial(g x)}{\partial l}$ would simply yield $\frac{\partial x}{\partial l}$.
} 
178

$$
\begin{aligned}
& \frac{\partial x(t, l)}{\partial t} \equiv-\frac{\partial(g(E(t), l) x(t, l))}{\partial l}-\delta(E(t), l) x(t, l)-u(t, l), \\
& x\left(t_{0}, l\right)=x_{0}(l), \quad g\left(E(t), l_{0}\right) x\left(t, l_{0}\right)=p\left(t, l_{0}\right), \quad p\left(t, l_{0}\right) \geq 0, \quad \leq u(t, l) \geq 0,
\end{aligned}
$$

where $E(t)$ is given by equation (2), and $r$ denotes the discount rate. The twice-differentiable function $B(x, u) e^{-r t}$ presents the discounted net benefits of the timber. It depends not only on the number of logged trees but also on the number of standing trees since it incorporates the maintenance cost of the forest. It is assumed that the maintenance cost function is concave, and thus $B_{x}<0, B_{x x}<0$. It is also assumed that the net benefit function is strictly concave in $u$. The twice-differentiable and strictly convex function $C(p) e^{-r t}$ expresses the discounted cost of nursing trees up to diameter $l_{0}$, the differentiable function $S^{t_{1}}(x) e^{-r t_{1}}$ the discounted value of the standing trees at the final point in time of the planning horizon, and the differentiable function $S^{l_{m}}(x) e^{-r t}$ expresses the discounted value of the standing trees that have reached the maximum diameter $l_{m} \cdot{ }^{6}$ The term $x_{0}(l)$ denotes the initial diameter distribution of the trees, and the restriction $g\left(E(t), l_{0}\right) x\left(t, l_{0}\right)=p\left(t, l_{0}\right)$ requires that the flux of the change in diameter at diameter $l_{0}$ multiplied by the tree density coincides with the total flux of the diameter of trees with diameter $l_{0}$. Finally, the control variables must be nonnegative.

Let the costate variable related with the dynamics of the forest be denoted by $\lambda(t, l)$, and the Lagrange multiplier related with the restriction $g\left(E(t), l_{0}\right) x\left(t, l_{0}\right)=p\left(t, l_{0}\right)$ by $\lambda_{0}(t)$. Utilizing Theorem 2 of Hritonenko et al. (2008) the following necessary conditions can be obtained:

\footnotetext{
${ }^{6}$ In the case of planting, the function $C(p)$ expresses the cost of planting trees with diameter $l_{0}$ and obviously has to be specified differently to how it is expressed in the case of natural reproduction.
} 


$$
\begin{aligned}
& e^{-r t} B_{u}-\lambda(t, l)+\mu_{1}(t, l)=0, \quad \forall t, \quad \forall l \\
& -e^{-r t} C^{\prime}\left(p\left(t, l_{0}\right)\right)+\lambda_{0}(t)+\eta(t)=0, \quad \forall t \\
& p\left(t, l_{0}\right)-g\left(E(t), l_{0}\right) x\left(t, l_{0}\right)=0, \quad \forall t
\end{aligned}
$$

$$
\frac{\partial x(t, l)}{\partial t}=-\frac{\partial(g(E(t), l) x(t, l))}{\partial l}-\delta(E(t), l) x(t, l)-u(t, l), \quad x(0, l)=x_{0}(l),
$$

$$
-\frac{\pi}{4} l^{2} \int_{l_{0}}^{l_{m}} \lambda(t, l)\left(\frac{\partial\left(g_{E} x(t, l)\right)}{\partial l}+\delta_{E} x(t, l)\right) d l,
$$$$
\frac{\partial \lambda(t, l)}{\partial t}+g(E(t), l) \frac{\partial \lambda(t, l)}{\partial l}=+(r+\delta(E(t), l)) \lambda(t, l)-B_{x}
$$

where $\mu_{1}$ and $\eta$ are Kuhn-Tucker multipliers related to the non-negativity constraints of the decision variables $u$ and $p$, respectively. For an interior solution the first necessary condition, equation (5) states that along the optimal path the discounted marginal net benefits of timber should equal the shadow price $\lambda$ (in situ value) of the forest stock for every $t$ and $l$. In contrast to lumped optimal control, distributed optimal control requires that this equation holds along the optimal path not only with respect to time, but also with respect to diameter. Thus, the forest manager maximizes his/her benefits not only over time but also with respect to diameter at every instant of time. In other words, the forest manager practices selective logging. Equation (6) states that the discounted marginal cost of nursing trees up to diameter $l_{0}$ should equal, at every moment of time the future marginal benefits of this "tree", i.e. the marginal net benefits that accrue from time $t$ to $t_{1}$. Hence, corresponding with the first necessary condition, the forest manager to some extent also practices selective nursing by choosing the time and the number of trees to be grown, but not their diameter. Equation (7) reproduces the constraint associated with $\lambda_{0}(t)$ and reflects the fact that the increase in diameter of the trees has to coincide with the flux of ingrowing trees with diameter $l_{0}$. Necessary condition (8) shows that the marginal change in the in situ value over time and diameter has to equal the sum of the forgone interest in capital in the form of trees, the monetary value of the lost trees due to natural mortality and the marginal maintenance cost plus the sum of the monetary 
values of the direct and indirect changes in growth and mortality of the standing trees. The last necessary condition is just a restatement of the law of motion, and therefore, it will not be discussed here. Finally, following Sage (1968) the following necessary transversality conditions have to be taken into account.

$$
\begin{aligned}
\lambda_{0}(t) & =\lambda\left(t, l_{0}\right), \\
\lambda\left(t_{1}, l\right) & =\frac{d S^{t_{1}}\left(x\left(t_{1}, l\right)\right)}{d x}, \\
g\left(E\left(t, l_{m}\right), l_{m}\right) \lambda\left(t, l_{m}\right) & =\frac{d S^{l_{m}}\left(x\left(t, l_{m}\right)\right)}{d x} .
\end{aligned}
$$

The first transversality condition, equation (10), requires at every moment that the shadow cost for nursing trees has to equal the shadow price of the stock evaluated at the diameter $l_{0}$. This transversality condition is a result of the link between the distributed and the boundary control formed by their common stock variable. The transversality condition (11) states that the shadow price of the trees has to equal the value of an additional standing "tree" at the end of the planning horizon. Finally, transversality condition (12) yields that the shadow price of the trees has to be equal to the value of an additional standing tree with the maximum diameter.

\section{Considerations in the long-run}

In this section we analyze to what extend the first order conditions (5) - (9) relate to the first order conditions of an even-aged forest, commonly expressed by the Faustmann formula. Moreover, we describe the optimal size distribution of the forest in the steady state, i.e. the steady state distribution of the forest.

\subsection{Comparison with the Faustmann formula}

From equation (5) we know for an interior solution that $e^{-r t} B_{u}(u, x)=\lambda(t, l)$, i.e., at every moment of time it is optimal to cut the number of trees in such a way that the discounted marginal net benefits of timber 
are equal to the in situ value of the standing trees. Hence, we can rewrite equation (8) to obtain a generalized

Faustmann equation.

\section{Proposition 1 (Generalized Faustmann Equation)}

The change in the in situ value of the stock density

$$
\begin{aligned}
\frac{\partial \lambda(t, l)}{\partial t}+ & \frac{\partial \lambda(t, l)}{\partial l} g(E(t), l)+B_{x}-\delta(E(t), l) \lambda(t, l)+ \\
\frac{\pi}{4} l^{2} \int_{l_{0}}^{l_{m}} \lambda(t, l)\left(\frac{\partial\left(g_{E} x(t, l)\right)}{\partial l}+\delta_{E} x(t, l)\right) d l & =r \lambda(t, l) .
\end{aligned}
$$

can be interpreted as a generalization of the Faustmann formula.

Demonstration: The right-hand side of equation (13) reflects the interest forgone on the capital tied up in the standing trees. The first two terms of the left-hand side reflect the change in the in situ value of the timber growing for an additional period of time and an increase in diameter by one unit. Given that $B_{x}<0$, the marginal maintenance cost for the stock not being cut down and the monetary loss due to natural mortality must be subtracted. Moreover, the monetary value of the direct and indirect changes of growth and mortality processes resulting from a change in the density have to be taken into account. Since these density dependent changes in growth and mortality are multiplied by the in situ value, the last term of the left-hand side provides a monetary value for these changes. The right-hand side and left-hand side have to be identical along the optimal path. To see that equation (13) reflects the Faustmann formula as a special case let us restate the Faustmann formula given by

$$
P_{w} f^{\prime}(T)=r P_{w} f(T)+\frac{r\left(P_{w} f(T)-c e^{r T}\right)}{e^{r T}-1},
$$

where $T$ indicates the age when the entire even-aged stand is cut, $P_{w}$ is the market price of the wood, $f(T)$ the merchantable volume of wood that a stand of age $T$ produces. The parameter $c$ presents transaction (logging, processing, transport) and nursing costs. 
The left-hand sides of the Faustmann formula and of equation (13) reflect the change in the in situ value of the forest over time. However, since equation (14) has to be interpreted differently from equation (13), we demonstrate in the appendix that in the case of an even-aged stand, the change in the in situ value over time - the equivalent of equation (13) - provides the Faustmann Formula. However, the traditional formula does not take into account the changes in maintenance costs and monetary values from changes in growth and mortality as a result of a change in the diameter of the standing trees. The term $P_{w} f(T)-c e^{r T}$ reflects the net value of the standing trees in the marketplace and corresponds to $\lambda(t=0, l)$ if $t_{1}$ is identical to $T$. As $t_{1}$ increases, future rotations of the forest stand are incorporated into the value of $\lambda(t, l)$ as it denotes the in situ value from $t$ to $t_{1}$. Specifically, it holds as $t_{1}$ tends to infinity and we obtain that the value of $\lambda(t, l)$ is given by $P_{w} f(T)-c e^{r T}+\frac{P_{w} f(T)-c e^{r T}}{e^{r t}-1}$, where the second term reflects the opportunity cost of the land for an infinite stand rotation. Hence, the change in the in situ value $d \lambda / d T$ is given by $P_{w} f^{\prime}(T)-r c e^{r T}$ and reflects the left-hand side of equation (14), and $r \lambda=r\left(P_{w} f(T)-c e^{r T}+\frac{P_{w} f(T)-c e^{r T}}{e^{r T}-1}\right)$ the right-hand side of equation (14) taking into account that the term $r c e^{r T}$ cancels out on both sides, i. e.,

$$
P_{w} f^{\prime}(T)=r P_{w} f(T)+\frac{r\left(P_{w} f(T)-c e^{r T}\right)}{e^{r t}-1}=r \lambda .
$$

Thus, based on the concept of the in situ value, equation (13) can be interpreted as a generalization of the traditional Faustmann formula, where the forest is distributed over the diameter of the trees. The interpretation of equation (13) collapses to the traditional Faustmann formula if $l$ and $E$ are considered constants, i.e., all derivatives with respect to $l$ and $E$ are zero.

In practical terms, it is not possible to determine whether the optimal rotation age for most trees is lower or higher under a selective cutting regime than under a clear cutting regime. The precise determination of the optimal rotation age for the trees under a selective cutting regime depends, in particular, on the density effect, on the development of the size of the trees over time, and on the price of timber as a function of the size of the tree. 


\subsection{Implications of a Steady state on the optimal long-run distribution.}

The first order conditions of problem (D) do not permit an analytical solution. To take the analysis further we consider the case where the forest has reached the steady state, i. e. $\partial \lambda / \partial t=0$ and $\partial x / \partial t=0$.

The optimal steady state problem is a lumped optimal control problem defined over diameter $l \in\left[l_{0}, l_{m}\right]$ where the density of trees with diameter $l$ is the control variable. This problem can be thought of as a situation where the private owner chooses the optimal diameter distribution of the trees in the steady state resulting from an exogenous shock. Thus, the optimal path of the stock variable $x(l)$ traces out the optimal steady state distribution. The assumption of an steady-state distribution implies that $E(t)$ is constant, i.e. the density effect is constant and $E(t)=E$. In this way, the integrodifferential equations (8) and (9) are ordinary differential equations and are mathematically tractable.

By suppressing $t$, equation (9) can be written as:

$$
g(E, l) \frac{d x}{d l}=-\left(\frac{d g(E, l)}{d l}+\delta(l)\right) x(l)-u(l), \quad x(0, l)=x_{0}(l)
$$

In the case where the benefit function is linear in $u(l)$, the system leads to a corner solution, that is, there exists a $\tilde{l} \in\left(l_{0}, l_{m}\right)$ where $u(\tilde{l})=x(\tilde{l})$, and $x(l)=0, \forall l>\tilde{l}$. Thus, equation (9), for $l<\tilde{l}$ can be written as

$$
\frac{d x}{d l}=\frac{-\left(\frac{d g(E, l)}{d l}+\delta(E, l)\right) x(l)}{g(E, l)} .
$$

Solving this equation yields

$$
x(l)=\frac{p\left(l_{0}\right)}{g(E, l)} \exp ^{l} \int_{l_{0}}^{l}-\frac{d g(E, s) / d s+\delta(s)}{g(E, s)} d s
$$

where we made use of the boundary condition $g\left(E, l_{0}\right) x\left(l_{0}\right)=p\left(l_{0}\right)$. Thus, the optimal long-run distribution 
will be increasing (decreasing) over the diameter $l$ if the absolute value of $\frac{d g(E, l)}{d l}$ is greater (lower) than $\delta(l)$

For the case of a low mortality rate and fast growing trees, the optimal steady state distribution is increasing in diameter, i.e., the proportion of large trees is relatively high. On the contrary, when the mortality is high and the growth rate is low, the optimal steady state distribution is decreasing in diameter, i.e., the proportion of large trees is relatively low.

\section{Empirical study}

In practice the necessary conditions (three equations and a system of partial integrodifferential equations) can only be solved analytically under severe restrictions with respect to the specification of the mathematical problem (Muzicant, 1980). Thus, one has to resort to numerical techniques to solve the distributed control problem. Available techniques such as the method of finite differences, the Galerkin method or that of finite elements may be appropriate choices (Calvo and Goetz, 2001). However, all of these methods require the programming of algorithms that are mostly unknown to economists. Therefore we propose a different method called the Escalator Boxcar Train (de Roos, 1988) to describe the evolution of physiologicallystructured populations. De Roos (1988) has shown that this technique is an efficient integration technique for structured population models. More details about this technique and how this approach can be extended to account for the incorporation of decision variables can be found in Goetz et al. (2008). The Escalator Boxcar Train (EBT) is based on converting the structuring variable into a state variable of the system by transforming the partial integrodifferential equation into ordinary differential equations over time. Moreover, EBT allows the density effect of the biological processes to be considered. In contrast to the other available methods, it can be implemented with standard computer software used to solve mathematical programming problems. 
subject to the constraints

The purpose of the empirical analysis is to determine the optimal selective-logging regime of a diameterdistributed forest, i.e., the selective logging regime that maximizes the discounted private net benefits from timber production of a stand of Pinus sylvestris (Scots pine) over a time horizon of 300 years. ${ }^{7}$ In this way it is possible to provide guidance for forest practitioners with respect to the optimal logging pattern, and the optimal long-run diameter distribution of the stand.

\subsection{Data and specification of functions}

In order to solve the decision problem (D) it needs to be transformed into a problem which can be solved numerically. For this purpose we define $i=0, \cdots, n$ cohorts over the diameter $l$, i.e., the trees whose diameters fall within the limits $l_{i}$ and $l_{i+1}$ are grouped in the cohort $i$. Hence we can define $X_{i}(t)$ as the number of trees, $L_{i}(t)$ as the average diameter, and $U_{i}(t)$ as the number of cut trees within the cohort $i . \bar{X}$, $\bar{L}$, and $\bar{U}$ denote the vectors $\bar{X}=\left(X_{0}, \cdots, X_{n}\right), \bar{L}=\left(L_{0}, \cdots, L_{n}\right)$, and $\bar{U}=\left(U_{0}, \cdots, U_{n}\right)$, respectively. The vector $\bar{X}^{0}$ denotes the initial density of each cohort. As demonstrated in Goetz et al. (2008), the decision problem (D) can be approximated to the decision problem (D') given by

$$
\begin{aligned}
\max _{\bar{U}(t), P(t)} & \int_{0}^{t_{1}} B(\bar{X}(t), \bar{L}(t), \bar{U}(t)) e^{-r t} d t-\int_{0}^{t_{1}} C(P(t)) e^{-r t} d t \\
& +\quad S^{t_{1}}\left(\bar{X}\left(t_{1}\right), \bar{L}\left(t_{1}\right)\right) e^{-r t_{1}}+\int_{0}^{t_{1}} S^{l}\left(X_{n}(t), L_{n}(t)\right) e^{-r t} d t
\end{aligned}
$$

\footnotetext{
${ }^{7}$ In countries at higher latitudes the species Pinus sylvestris is often considered as shade intolerant, and consequently not suitable for a selective logging regime. However, in countries at mid-range latitudes like Spain natural reproduction requires that older trees protect young trees against heat and water stress in the summer (personal communication by C. Gracia, University of Barcelona, Department of Ecology and CREAF, the Centre for Ecological Research and Forestry Applications). This finding is supported by field experiments reported by Clapham et al. (2002) and Sanchez-Gomez et al. (2006).
} 
328

$$
\begin{aligned}
\frac{d X_{i}(t)}{d t} & =-\delta\left(\tilde{E}(t), L_{i}\right) X_{i}(t)-U_{i}(t), \quad \frac{d L_{i}(t)}{d t}=g\left(\tilde{E}(t), L_{i}\right) \\
\frac{d X_{0}}{d t} & =-\delta\left(\tilde{E}(t), l_{0}\right) X_{0}(t)-\frac{d}{d l} \delta\left(\tilde{E}(t), l_{0}\right) L_{0}(t)+P(t) \\
\frac{d L_{0}}{d t} & =g\left(\tilde{E}(t), l_{0}\right) X_{0}(t)+\frac{d}{d l} g\left(\tilde{E}(t), l_{0}\right) L_{0}(t)-\delta\left(\tilde{E}(t), l_{0}\right) L_{0}(t) \\
X_{i}(0) & =\bar{X}^{0}, \quad g\left(\tilde{E}(t), l_{0}\right) x\left(t, l_{0}\right)=P(t), \quad U_{i}(t), P(t) \geq 0 \quad U_{i}(t) \leq X_{i}(t),
\end{aligned}
$$

where $p\left(t, l_{0}\right)$ is now written as $P(t)$ to unify the notation. The term environment $\tilde{E}(t)$ is determined by

$$
\tilde{E}(t)=\sum_{i=0}^{n} \pi\left(\frac{L_{i}}{2}\right)^{2} X_{i}(t) .
$$

For given specifications of the economic and biophysical functions of the model, and a given initial diameter distribution of the trees, $\bar{X}^{0}$, a numerical solution of the decision problem (D') can be obtained. To analyze the sensitivity of the optimal logging regime with respect to a change in the initial diameter distribution, we consider different initial diameter distributions. They were specified as a transformed beta density function $\theta(l)$ with shape parameters $\gamma$ and $\phi$ (Mendenhall et al., 1990). The initial forest consists of a population of trees with diameters within the interval $0 \mathrm{~cm} \leq l \leq 50 \mathrm{~cm}$. The distribution of the diameter of the trees is given by:

$$
\theta(l ; \gamma, \phi)= \begin{cases}\frac{1}{50} \frac{\Gamma(\gamma+\phi)}{\Gamma(\gamma) \Gamma(\phi)}\left(\frac{l}{50}\right)^{\gamma-1}\left(1-\frac{l}{50}\right)^{\phi-1}, & \gamma, \phi>0 ; 0 \leq l \leq 50 \\ 0, & \text { elsewhere }\end{cases}
$$

where $\theta(l ; \gamma, \phi)$ denotes the density function of the diameter of trees. Thus, the integral $\int_{l_{i}}^{l_{i+1}} \theta(l ; \gamma, \phi) d l$ gives the proportion of trees lying within the range $\left[l_{i}, l_{i+1}\right)$. The beta density function is used because it is defined over a closed interval and allows a great variety of distinct shapes of the initial diameter distributions of the trees to be defined. We defined $l_{0}=0$ and $l_{m}=80$. Within this interval we concentrate on the interval 
$[0,50]$ and divide it into 10 initial subintervals of identical length. In this way, each cohort comprises trees that differ in their diameter by a maximum of $5 \mathrm{~cm}$, and can therefore be considered as homogeneous. The initial number of trees in each cohort, $X_{i}(0), i=1, \cdots, n$, is calculated in such a way that the basal area of the stand is constant $\left(25 \mathrm{~m}^{2} / \mathrm{ha}\right)$ in order to allow for comparisons between the results of the different optimization outcomes.

The function $B(\bar{X}(t), \bar{L}(t), \bar{U}(t))$ accounts for the net benefits of the timber at time $t$ and is defined as: $\left[\sum_{i=0}^{n}\left(\rho\left(L_{i}(t)\right)-v c\right) t v\left(L_{i}(t)\right) m v\left(L_{i}(t)\right) U_{i}(t)\right]-[m c(X(t))]$, where $X(t)=\sum_{i=0}^{n} X_{i}(t)$. The first term in square brackets denotes the sum of the revenue of the timber sale minus the cutting cost of each cohort $i$, and the second term, $m c(X(t))$, accounts for the maintenance cost. The parameter $\rho\left(L_{i}\right)$ denotes the timber price per cubic meter of wood as a function of the diameter, $t v\left(L_{i}\right)$ is the total volume of a tree as a function of its diameter, $m v\left(L_{i}\right)$ is the part of the total volume of the tree that is marketable and $v c$ is the variable cutting cost.

Timber price per cubic meter was taken from a study by Palahí and Pukkala (2003), who analyzed the optimal management of a Pinus sylvestris forest in a clear-cutting regime. They estimated a polynomial function given by $\rho(L)=\operatorname{Min}[-23.24+13.63 \sqrt{L}, 86.65]$, which is an increasing and strictly convex function, for a diameter lower than $65 \mathrm{~cm}$. At $L=65$ the price reaches its maximum value, thus, it is considered constant for $L>65$. Data about costs were provided by the consulting firm Tecnosylva, which elaborates forest management plans throughout Spain. The logging cost comprises logging, delimbing, and collecting and removing the residues, and it is given by $v c=15$ euros per cubic meter of logged timber. The maintenance cost is an increasing function of the number of stems per hectare, and is given by $m c(X)=10+0.0159 X+0.0000186 X^{2}$. The nursing cost is linear in the amount of ingrowing trees and is given by $C(P)=0.73 P$.

The value of the parameters of tree volume, $t v\left(L_{i}\right)$, and the marketable part of the tree volume, $m v\left(L_{i}\right)$, are estimated using information provided by a study by Cañellas et al. (2000). The tree volume follows 
the allometric relation $t v(L)=0.00157387 L^{1.745087}$, and the marketable part of the volume of timber of each tree is an increasing function of the diameter, given by $m v(L)=0.699+0.0004311 L$. The thinning and nursing period, $\triangle t$, is set equal to 10 years, which is a common practice for a Pinus sylvestris forest (Cañellas et al., 2000).

To determine the dynamics of the forest the growth of a diameter-distributed stand of Pinus sylvestris without thinning was simulated with the bio-physical simulation model GOTILWA (Growth Of Trees Is Limited by Water $^{8}$ ). About 100 different simulation runs were conducted by varying the initial diameter distribution. The results of the simulation were used to estimate the function $g\left(E, L_{i}\right)$, which describes the rate of diameter change. It was specified as a von Bertalanffy growth curve (von Bertalanffy, 1957), generalized by Millar and Myers (1990) which allows the rate of growth of the diameter to vary with environmental conditions. Thus, the function $g\left(E, L_{i}\right)=\left(l_{m}-L_{i}\right)\left(\beta_{0}-\beta_{1} B A\right)$ was estimated by the method of $O L S$, where $\beta_{0}$ and $\beta_{1}$ are proportionality constants, and $B A$ is the sum of the basal area of all trees. The estimation yielded the growth function: $g\left(E, L_{i}\right)=\left(80-L_{i}\right)(0.0070177-0.000043079 B A)$. Other functional forms of $g\left(E, L_{i}\right)$ were evaluated as well, but they explained the observed variables to a lesser degree. ${ }^{9}$

As GOTILWA only allows the survival or death of an entire cohort to be simulated but not the survival or death of an individual tree, it was not possible to obtain an adequate estimation of the function $\delta\left(E, L_{i}\right)$ describing the mortality of the forest. Nevertheless, the information provided by Tecnosylva suggests that in a managed forest, the mortality rate can be considered almost constant over time and independent of the diameter. Thus, according to the data supplied by Tecnosylva, $\delta\left(E, L_{i}\right)$ was chosen to be constant over time

\footnotetext{
${ }^{8}$ This program has been developed by C. Gracia and S. Sabaté, University of Barcelona, Department of Ecology and CREAF (Centre de Recerca Ecològica i Aplicacions Forestals), Autonomous University of Barcelona, respectively. It simulates growth and mortality and allows one to explore how the life cycle of an individual tree is influenced by the climate, the characteristics of the tree itself and environmental conditions given by the total basal area of the trees. The model is defined by 11 input files specifying more than 90 parameters related to site, soil composition, tree species, photosynthesis, stomatal conductance, forest composition, canopy hydrology, and climate.

${ }^{9}$ The discretization scheme employed has the advantage that the set of ordinary difference equations is derived from the underlying partial integro-differential equation, whereas in previous literature, for example (Haight et al., 1985), the set of ordinary difference equations was set up ad hoc. Moreover, the EBT method requires only the differential equation $d l / d t=g(\cdot)$ to be estimated, whereas the approach followed in the previous literature would require a complex system of difference equations to be estimated simultaneously.
} 
and equal to 0.01 for each cohort.

\subsection{Optimization results}

The mathematical optimization problem (D') was programmed in GAMS (General Algebraic Modeling System) (Brooke et al., 1992). For the numerical solution of this problem the Conopt3 solver, available within GAMS, was employed. For a given initial distribution, the numerical solution of the problem determines for every 10-year period the optimal logging, $U_{i}$, and planting, $P$; the optimal values of the state variables, $X_{i}$ and $L_{i}$; and consequently, economic variables, such as the revenue from timber sales and the cutting, planting, and maintenance costs. Optimizations with different random initializations of the control variables were carried out to assure that the numerical method provides solutions that are independent of the initially chosen values for the numerical optimization technique. All optimizations were carried out on a per-hectare basis.

\section{Selective Logging Regime}

Forest managers who want to maximize net timber benefits have to decide on the intensity of cutting, that is, how many trees of diameter $L_{i}$ have to be cut at each moment of time. To calculate the optimal logging regime we assume that the initial diameter distribution of the trees is given by a beta density function with parameters $\gamma=0.8$ and $\phi=0.2$, corresponding to a young forest distribution. Table 1 summarizes the results of the optimization where a discount rate of $2 \%$ was assumed. It can be observed that all economic and biophysical variables show a cyclical pattern over time in which the phase of the pattern is maintained over time, but the amplitude decreases. In the long-run, the forest consists of approximately 927 trees, and approximately 123 of these trees are logged each 10-year period. The volume of the logged trees is 73.64 $\mathrm{m}^{3}$, of which $52.43 \mathrm{~m}^{3}$ is marketable timber. The current-value revenue from the sale of this amount of timber minus the logging cost is approximately 1900 euros per hectare. The current-value net benefits of the forest in the long run are nearly 1000 euros. Following this regime, the total sum of discounted net benefits 
Table 1

To illustrate the optimal evolution of the forest, Figure 1 a) to f) depicts the change in the histogram of the forest distribution over the planning horizon. It must be noted that the width of the diameter intervals is only homogeneous at the initial point in time, but the width of the different cohorts changes with the evolution of the forest over time. Thus, the size of the bar of a particular cohort is chosen so that its area corresponds to the number of trees in that cohort. The slightly shaded bars indicate the number of trees that should be logged within each 10-year period, while the heavily shaded bars stand for the number of trees that should remain in the stand. Figure 1 shows that the initially skewed diameter distribution is gradually flattened over time. However, during this process the distribution varies in the form of a wave leading to an almost u-shaped distribution after 50 years. Figure 1 also shows that it takes more than 100 years to reach a diameter distribution of the trees which is relatively stable. ${ }^{10}$

\section{Figure 1}

\section{Effects of a Change in the Initial Diameter Distribution on the Optimal Selective-Logging Regime}

To illustrate how the initial diameter distribution of the trees alters the optimal selective logging regime, problem (D') has also been solved for an old forest distribution $(\gamma=2, \phi=0.8)$, a bell shaped distribution $(\gamma=\phi=2)$, a U-shaped distribution $(\gamma=\phi=0.5)$, a uniform distribution $(\gamma=\phi=1)$ and a nonstructured forest (even-sized, $\gamma=\phi=\infty$ ). Figure 2 depicts the optimal evolution of the weighted average (2a) and standard deviation (2b) of the diameter distribution over time for the analyzed initial distributions. ${ }^{11}$

\footnotetext{
${ }^{10}$ Please note that the average diameter of the bars (cohorts) is not constant over time. This is explained by the fact that the trees of a cohort always stay together and do not move from one cohort to another. However, since the trees grow the average diameter of the cohort increases as the cohort moves along the time axis.

${ }^{11}$ Figure 2 shows the development of the average and standard deviation of the diameter distribution of three different initial diameter distributions. The remaining three initial diameter distributions are not depicted because they follow the same pattern, and their graphical representation would obstruct the interpretation of Figure 2.
} 
It shows that the average diameter of the different distributions tends to converge after approximately 200 years, as the amplitude and phase of the cyclical behavior vanishes. Additionally, Figure 2 shows that the standard deviation of the distributions is governed by the same cyclical pattern. When the mean diameter and standard deviation of the initial diameter distribution are close to that of the steady state (young forest with $\gamma=0.8, \phi=2$ ), the cyclical evolution of these variables is less pronounced, implying that the benefits will be more stable over time. In general, it can be observed that the long-run mean and standard deviation tend to the values of 17 and 9, respectively, for all considered parameter values of $\gamma$ and $\phi$ of the diameter distribution. Hence, the steady-state distribution of the diameter of the trees is independent of the initial distribution of the trees. This result confirms the supremacy of the normal forest as the optimal forest management objective.

Figure 2

Moreover, we conducted a sensitivity analysis to determine the effect of a change in the initial basal area on the steady-state distribution. Figure 3 illustrates the optimal evolution of the weighted average diameter (3a) and the standard deviation (3b) of the diameter over time for a young forest, given the initial basal areas of 15,25 and $35 \mathrm{~m}^{2} / \mathrm{ha}$. One can see from Figure 3 that the long-run mean and standard deviation tend to the same values as in Figure 2 (17 and 9, respectively). This result shows that the steady-state distribution is not only independent from the initial diameter distribution but is also independent from the initial basal area.

\section{Figure 3}

We also conducted a sensitivity analysis to evaluate how the optimal management regime of a forest changes as a result of a variation in the discount rate. Thus, we solved problem (D') for a young forest distribution, given discount rates of $3 \%$ and $4 \%$. Figure 4 depicts the optimal evolution of the mean diameter (4a) and standard deviation (4b) over time resulting from the optimizations. Figure 4 shows that the discount rate has a significant influence on the optimal selective logging regime. An increase in the discount rate produces, 
in the long run, a decrease in the average diameter at which the trees are cut, that is, the trees are cut earlier. However, it can be observed in Figure 4b that the initial diameter distributions stabilize in the long run, independently of the chosen discount rate, i.e., the steady state distribution is independent of the discount rate.

Figure 3

At the end of section 3.2 we stated that the shape of the distribution at the steady state depends on growth and mortality rates. To illustrate this point, the optimal selective logging regime in the case of an initial diameter distribution of trees corresponding to a young forest is calculated for a higher mortality rate of $\delta=0.1$ compared to the previously chosen mortality rate of 0.01 . The histogram of the resulting long-run distribution is depicted in Figure 5. It shows that an increase in the mortality rate causes the optimal steadystate distribution to be decreasing in diameter.

\section{Figure 5}

Our results show that in the presence of density effects the steady state distribution tends to a normal forest and is independent of the initial distribution of trees. For a comparison of our results with the previous results in the literature we refer primarily to the article by Salo and Tahvonen (2002) since the employed model is still the up-to-date cornerstone for other works. In the results of their work the optimal long-run age distribution is non cyclical only when the length of the discretely measured time period converges towards zero, when the discount rate is zero or when the Faustmann rotation is not unique. Under these conditions a normal forest may result. Otherwise many other outcomes, which do not correspond to a normal forest are possible. Salo and Tahvonen (2002) observe that the analytical framework of a time discrete model is the principal cause for the emergence of logging cycles. The model presented in this article is based on a different analytical framework, which allows relaxing assumptions made by Salo and Tahvonen (2002): the stand is structured with respect to diameter, the economically more relevant variable, and not age; the 
cleared land does not have to be replanted immediately; the forest manager can vary the number of planted trees per hectare; and it allows partial harvesting of a cohort. Uusivuori and Kuuluvainen (2005) used an analytical framework very similar to Salo and Tahvonen (2002) but allowed also for partial harvesting of the different age classes, leading to long-run distributions being either cyclical or not. According to their findings the noncyclical forest is typically not a normal forest. However, the authors assume in contrast, to this study, and to the article by Salo and Tahvonen (2002), that the price for one cubic feet of timber is independent of the age of the trees. As mentioned above the price of timber per cubic feet usually increases with the diameter (age) of the trees since the wood can be used for the production of more valuable goods. One would expect this assumption to affect the optimal logging regime. For this reason, and due to the fact that trees in the model of Uusivuori and Kuuluvainen (2005) do not only provide timber but also amenity values, it is not possible to compare their results with the results of the cited literature.

\section{Conclusions}

This article presents a theoretical model that allows us to determine the optimal management of a diameterdistributed forest where the growth process of the trees depends not only on their individual sizes but also on the size distribution of the trees within the entire stand. This modeling framework allows us to take into account the fact that the life cycle of each individual tree is affected by the other trees since they compete for light, nutrients, and space. The density dependent formulation of the biological growth process leads to a partial integrodifferential equation. To determine the optimal forest management, the corresponding economic decision problem can be formulated as a distributed optimal control problem where the control variables and the state variable depend on both time and the diameter of the trees.

The resulting necessary conditions of this problem allow the derivation of an analytical expression which can be interpreted as a generalization of the Faustmann formula. Since the necessary conditions of this problem include a system of partial integrodifferential equations, it usually cannot be solved analytically. 
Thus, the Escalator Boxcar Train method is proposed to solve the problem numerically. The method allows the partial integrodifferential equation to be transformed into a set of ordinary differential equations and thereby approximate the distributed optimal control problem by a standard optimal control problem. In contrast to the existing literature, the resulting optimization problem can be solved numerically using standard mathematical programming techniques and does not require programming complex numerical algorithms.

To determine the optimal selective logging regime of a diameter-distributed and privately owned forest where individual trees compete for scarce resources, an empirical analysis is conducted. It shows that the long-run mean and variance of the diameter distribution for the different types of analyzed forests considered tend to a common value, giving rise to a normal forest. Although the diameter distribution of the forests in the steady-state is independent of the initial distribution, the competition between individuals belonging to the same population affects the transition paths to the steady-state distribution, and therefore the optimal selective-logging regimes in the first periods differ considerably depending on the distribution of the individual characteristics over the entire population. 


\section{Appendix}

In the case of an even-aged stand decision problem and an infinite planning horizon, problem (D) can be simplified, and is given by

$$
\max _{u(t)} \int_{0}^{\infty} \tilde{B}(x(t), u(t)) e^{-r t} d t
$$

subject to the constraints

$$
\dot{x}(t)=\tilde{g}(x(t))-u(t), \quad x(0)=x_{0}, \quad u(t) \geq 0 .
$$

The state and control variables do not depend anymore on the diameter $l$ and since all trees are planted at the same time, the planting costs can be incorporated into the net benefit function of the timber, $\tilde{B}(x(t), u(t))$. Moreover, the residual value of the stand approaches zero as $t$ approaches infinity, and $\tilde{g}(x(t))$ denotes the growth of the biomass. With these provisions the current value Hamiltonian, $\mathcal{H}^{D E}$, yields $\mathcal{H}^{D E}=$ $\tilde{B}(x, u)+\lambda(\tilde{g}(x)-u)$ and the first order conditions are given by

$$
\begin{aligned}
\mathcal{H}_{u}^{D E} & =\tilde{B}_{u}-\lambda+\mu_{1}=0, \\
\dot{\lambda} & =r \lambda-\tilde{B}_{x}, \quad \lim _{t \rightarrow \infty} \lambda(t)=0 \\
\dot{x} & =\tilde{g}(x)-u, x(0)=x_{0} .
\end{aligned}
$$

\footnotetext{
Unfortunately, this formulation does not allow the Faustmann formula to be derived. Yet, a redefinition of the variables yields an equivalent model that in turn provides the Faustmann formula. Let $x(t)=T(t)$, and therefore $\dot{x}=\dot{T}$, $\lambda(t)=\varphi(t)$, where $\varphi$ is the new costate variable,

$u(t)=1-I(t)$, where $0 \leq I \leq 1$ indicates the share of trees that is invested, i.e. not cut, $\dot{x}=\tilde{g}(x)-u=1-(1-I)=I$, where $\tilde{g}(x) \equiv 1$, and given the previous definitions we obtain $\dot{T}=I$, $\tilde{B}(x, u)=r F(t)(1-I)$, where $F(T)=P_{w} f(T)-c e^{r T}+v$. The parameter $v$ denotes the land expectation or site value.
} 
546

Thus, the new decision problem formulated originally by Weitzman (2003) yields

$$
\max _{I(t)} \int_{0}^{\infty} r\left(F(T(t))(1-I(t)) e^{-r t} d t,\right.
$$

subject to the constraints

$$
\dot{T}(t)=I(t), \quad T(0)=0, \quad 0 \leq I(t) \leq 1 .
$$

The current value Hamiltonian, $\mathcal{H}^{D F}$, yields $\mathcal{H}^{D F}=r F(T)(1-I)+\varphi I$ and the first order conditions result in

$$
\mathcal{H}_{I}^{D F}=r F(T)-\varphi+\mu_{2}=0
$$

$$
\dot{\varphi}=r \varphi-r F^{\prime}(T)(1-I)
$$

$$
\dot{T}=I \text {. }
$$

Utilizing the substitution we made for the formulation of the decision problem (DE) in the first order conditions of problem (DE) shows that equations (A. 1) - (A.3) are identical to the first order conditions (A. 4) - (A. 6) of problem (DF). Hence, their solutions are identical. Utilizing equation (A.4) we see that $\varphi=r F(T)+\mu_{2}$. Hence, $\dot{\varphi}=r F^{\prime}(T) \dot{T}+\mu_{2}$. Substituting this expression in equation (A. 5) and using equation (A. 6) yields

$$
r F^{\prime}(T) I+\dot{\mu}_{2}=r^{2} F(T)+\mu_{2}-r F^{\prime}(T)(1-I) .
$$

Thus,

$$
\dot{\mu}_{2}=r^{2} F(T)+\mu_{2}-r F^{\prime}(T) .
$$

As long as $I>0$, i.e., we do not cut, $\mu_{2}$ will be zero and we obtain

$$
r=\frac{F^{\prime}(T)}{F(T)}=\frac{P_{w} f^{\prime}(T)-r c e^{r T}}{P_{w} f(T)-c e^{r T}+v} .
$$




$$
P_{w} f^{\prime}(T)=r P_{w} f(T)+\frac{r\left(P_{w} f(T)-c e^{r T}\right)}{e^{r T}-1},
$$

555 556 557 given by for an even-aged stand.

As shown by Weitzman (2003), equation (A.9) is identical to the reformulation of the Faustmann formula

where $v$ has been replaced by the maximum site value $\frac{P_{w} f(T)-c}{e^{-r T}-1}$. Hence we can conclude that given the optimal value of $I$, equation (A.2), which is equivalent to equation (A. 5), provides the Faustmann formula 


\section{References}

Adams, D., Alig, R., McCarl, J., Callaway, J. and Winnett, S. (1996). An analysis of the impacts of public timber harvest policies on the private forest management in the United States, Forest Science 42: 343 358.

Adams, D. and Ek, A. (1974). Optimizing the management of uneven-aged forest stands, Canadian Journal of Forest Research 4: 274-287.

Björklund, L. (1999). Identifying heartwood-rich stands or stems of Pinus Sylvestris by using inventory data, Sylva Fennica 33: 119-129.

Brooke, A., Kendrick, D. and Meeraus, A. (1992). GAMS: A User's Guide, release 2.25, The Scientific Press, San Francisco.

Cañellas, I., Martínez García, F. and Montero, G. (2000). Silviculture and dynamics of Pinus Sylvestris L. stands in Spain, Investigación Agraria: Sistemas y Recursos Forestales 9: 233-254.

Calvo, E. and Goetz, R. (2001). Using distributed optimal control in economics: A numerical approach based on the finite element method, Optimal Control Applications and Methods 22(5/6): 231-249.

Clapham, D.H., Ekberg, I., Eriksson, G., Norell, L. and Vince-Prue, D. (2002). Requirement for far-red light to maintain secondary needle extension growth in northern but not southern populations of Pinus sylvestris (Scots pine), Physiologia Plantarum 114: 207-212.

Cunha e Sa, M., Costa-Duarte, S. and Rosa, R. (2007). Forest vintages and carbon sequestration, manuscript, Faculdade de Economia, Universidade Nova de Lisboa, Portugal.

Cushing, J. (1988). An Introduction to Structured Population Dynamics, Society for Industrial and Applied Mathematics, Philadelphia.

de Roos, A. (1988). Numerical methods for structured population models: The Escalator Boxcar Train, Numerical Methods for Partial Differential Equations 4: 173-195.

de Roos, A. (1997). A gentle introduction to physiologically structured population models, in S. Tuljapurkar and H. Caswell (eds), Structured Population Models in Marine, Terrestrial and Freshwater Systems, Chapman and Hall, New York, chapter 5, pp. 119-204.

Doyon, F., Gagnon, D. and Giroux, J. (2005). Effects of strip and single-tree selection cutting on birds and their habitat in a southwestern Quebec northern hardwood forest, Forest Ecology and Management 209(1-2): 101-116.

Feichtinger, G. and Hartl, R. (1986). Optimale Kontrolle ökonomischer Prozesse, Walter de Gruyter, Berlin.

Feichtinger, G., Prskawetz, A. and Veliov, V. (2004). Age-structured optimal control in population economics, Theoretical Population Biology 65: 373-387. 
García-Abril, A., Martin-Fernández, S., Grande, M. and Manzanera, J. (2007). Stand structure, competition and growth of Scots pine (Pinus Silvestris L. in a Mediterranean mountainous environment, Annals of Forest Science 64: 825-830.

Goetz, R., Hritonenko, N., Xabadia, A. and Yatsenko, Y. (2008). Using the Escalator Boxcar Train to determine the optimal management of a size-distributed forest when carbon sequestration is taken into account, in I. Lirkov (ed.), Lecture Notes in Computer Science, Proceedings of the Sixth International Conference on "Large Scale Scientific Computations", Springer, Berlin, pp. 334-341.

Haight, R. (1987). Evaluating the efficiency of even-aged and uneven-aged stand management, Forest Science 33: 116-134.

Haight, R., Brodie, J. and Adams, D. (1985). Optimizing the sequence of diameter distributions and selection harvests for uneven-aged stand management, Forest Science 31: 451-462.

Hritonenko, N., Yatsenko, Y., Goetz, R. and Xabadia, A. (2008). Maximum principle for a size-structured model of forest and carbon sequestration management, Applied Mathematics Letters 21: 1090-1094.

Hunter, M. (1990). Wildlife, Forests, and Forestry: Principles of Managing Forest for Biodiversity, Prentice Hall, Englewood, NJ.

Karlsson, C. and Örlander, G. (2000). Soil scarification shortly before a rich seed-fall improves seedling establishment in seed tree stands of Pinus sylvestris, Scandinavian Journal of Forest Research 15: 256266.

Keyfitz, N. (1968). Introduction to the mathematics of population, Addison-Wesley, New York.

Keyfitz, N. (1977). Applied Mathematical Demography, Wiley.

Lin, C. and Buongiorno, J. (1998). Tree diversity, landscape diversity, and economics of maple-birch forests: Implications of Markovian models, Management Science 44(10): 1351-1366.

McKendrick, A. (1926). Application of mathematics to medical problems, Proceedings of the Edinburgh Mathematical Society 44: 98-130.

Mendenhall, W., Wackerly, D. and Scheaffer, R. (1990). Mathematical Statistics with Applications, 4 edn, PWS-Kent, Boston.

Metz, J. and Diekmann, O. (1986). The dynamics of physiologically structured populations, Springer Lecture Notes in Biomathematics, Springer-Verlag, Heidelberg.

Millar, R. and Myers, R. (1990). Modelling environmentally induced change in growth for Atlantic Canada cod stocks, International Council Exploration Sea C.M./G24.

Mitra, T. and Wan, H. (1985). Some theoretical results on the economics of forestry, Review of Economic Studies LII: 263-282.

Mitra, T. and Wan, H. (1986). On the Faustmann solution to the forest management problem, Journal of Economic Theory 40: 229-249. 
Muzicant, J. (1980). Systeme mit verteilten Parametern in der Bioökonomie, Dissertation, Technische Universität Wien.

Palahí, M. and Pukkala, T. (2003). Optimising the management of Scots Pine (Pinus sylvestris L.) stands in Spain based on individual-tree models, Annals of Forest Science 60: 105-114.

Sage, A. (1968). Optimum Systems Control, Prentice Hall, New York.

Salo, S. and Tahvonen, O. (2002). On equilibrium cycles and normal forests in optimal harvesting of tree vintages, Journal of Environmental Economics and Management 44: 1-22.

Sanchez-Gomez, D., Zavala, M.A. and Valladares, F. (2006). Seedling survival responses to irradiance are differentially influenced by low-water availability in four tree species of the iberian cool temperateMediterranean ecotone, Acta Oecologica 30: 322-332.

Sawadogo, L., Tiveau, D. and Nygard, R. (2005). Influence of selective tree cutting, livestock and prescribed fire on herbaceous biomass in the savannah woodlands of Burkina Faso, Agriculture, Ecosystems and Environment 105(1-2): 335-345.

Scarpa, R., Hutchinson, W., Chilton, S. and Buongiorno, J. (2000). Importance of forest attributes in the willingness to pay for recreation: a contingent valuation study of Irish forests, Forest Policy and Economics 1: 315-329.

Sedjo, M. and Lyon, K. (1990). The long-term adequacy of world timber supply, Working paper Resources for the Future, Washington, DC.

Seymour, R. and Kenefic, L. (1998). Balance and sustainability in multiaged stands: a northern conifer case study, Journal of Forestry 96(7): 12-17.

Trasobares, A., Tomé, M. and Pukkala, T. (2004). Growth and yield model for Pinus halepensis Mill. in Catalonia, north-east Spain, Forest Ecology and Management 203: 49-62.

Uusivuori, J. and Kuuluvainen, J. (2005). The harvesting decision when a standing forest with multiple age-classes has value, American Journal of Agricultural Economics 87(1): 61-76.

Vanclay, J. (1995). Growth models for tropical forests: a synthesis of models and methods, Forest Science 41: $7-42$.

von Bertalanffy, L. (1957). Quantitative laws in metabolism and growth, Quarterly Review of Biology 32: 217-231.

Wan, H. (1994). Revisiting the Mitra-Wan tree farm, International Economic Review 35: 193-198.

Weintraub, A., Romero, C., Bjørndal, T. and Epstein, R. (2007). Handbook of Operations Research in Natural Resources, Springer, NY, pp.315-544.

Weitzman, M. (2003). Income, Wealth, and the Maximum Principle, Harvard University Press, Cambridge, MA. 
Whittam, R., McCracken, J., Francis, C. and Gartshore, M. (2002). The effects of selective logging on nestsite selection and productivity of hooded warblers (Wilsonia citrina) in Canada, Canadian Journal of Zoology 80(4): 644-654. 
Table 1: Optimal Selective-Logging Regime (where the initial diameter distribution is determined by $\gamma=0.8$ and $\phi=2$ )

\begin{tabular}{|c|c|c|c|c|c|c|c|c|c|c|c|}
\hline \multirow[b]{2}{*}{ Year } & \multirow[b]{2}{*}{$\begin{array}{c}\text { Number } \\
\text { of trees }^{(a)} \\
\end{array}$} & \multirow[b]{2}{*}{$\begin{array}{c}\text { Planted } \\
\text { trees }\end{array}$} & \multicolumn{5}{|c|}{ Logging } & \multirow{2}{*}{$\begin{array}{c}\text { Maintenance } \\
\text { cost } \\
\text { (Euros/ha) }\end{array}$} & \multirow{2}{*}{$\begin{array}{c}\text { Planting } \\
\text { cost } \\
\text { (Euros/ha) } \\
\end{array}$} & \multirow{2}{*}{$\begin{array}{c}\text { Net } \\
\text { benefit } \\
\text { (Euros/ha) } \\
\end{array}$} & \multirow{2}{*}{$\begin{array}{l}\text { Discounted } \\
\text { net benefit } \\
\text { (Euros/ha) } \\
\end{array}$} \\
\hline & & & $\begin{array}{c}\text { Logged } \\
\text { trees } \\
\end{array}$ & $\begin{array}{c}\mathrm{BA} \\
\left(\mathrm{m}^{2} / \mathrm{ha}\right) \\
\end{array}$ & $\begin{array}{l}\text { Volume } \\
\left(\mathrm{m}^{3} / \mathrm{ha}\right)\end{array}$ & $\begin{array}{l}\text { Timber } \\
\left(\mathrm{m}^{3} / \mathrm{ha}\right)\end{array}$ & $\begin{array}{c}\text { Revenue - log- } \\
\text { ging cost }\left(\text { Euros/ha) }{ }^{(b)}\right.\end{array}$ & & & & \\
\hline  & 820 & 202 & $\overline{1115}$ & $\bar{~} 12.43$ & 988.78 & 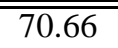 & 3211.29 & -355.74 & -121.19 & 2734.36 & 2734.36 \\
\hline 10 & 947 & 107 & 67 & 5.05 & 42.19 & 30.05 & 1127.83 & -417.68 & -64.33 & 645.81 & 529.79 \\
\hline 20 & 959 & 119 & 85 & 5.89 & 49.74 & 35.41 & 1274.32 & -424.12 & -71.48 & 778.71 & 524.05 \\
\hline 30 & 964 & 132 & 105 & 6.79 & 57.78 & 41.11 & 1430.57 & -426.60 & -79.13 & 924.85 & 510.58 \\
\hline 40 & 958 & 144 & 129 & 7.94 & 68.06 & 48.40 & 1642.03 & -423.27 & -86.52 & 1132.23 & 512.78 \\
\hline 50 & 939 & 137 & 154 & 9.19 & 79.06 & 56.20 & 1874.82 & -413.53 & -82.11 & 1379.18 & 512.40 \\
\hline 60 & 929 & 133 & 137 & 8.16 & 70.17 & 49.88 & 1662.47 & -408.81 & -79.52 & 1174.14 & 357.86 \\
\hline 70 & 935 & 163 & 118 & 8.50 & 71.39 & 50.83 & 1872.41 & -411.57 & -97.50 & 1363.34 & 340.87 \\
\hline 80 & 909 & 121 & 179 & 12.94 & 108.66 & 77.37 & 2850.05 & -398.61 & -72.45 & 2378.99 & 487.95 \\
\hline 90 & 921 & 129 & 100 & 7.18 & 60.31 & 42.94 & 1576.15 & -404.48 & -77.07 & 1094.59 & 184.18 \\
\hline 100 & 929 & 136 & 111 & 7.93 & 66.69 & 47.49 & 1738.22 & -408.63 & -81.17 & 1248.42 & 172.32 \\
\hline$\vdots$ & $\vdots$ & $\vdots$ & $\vdots$ & $\vdots$ & $\vdots$ & $\vdots$ & $\vdots$ & $\vdots$ & $\vdots$ & $\vdots$ & $\vdots$ \\
\hline 200 & 928 & 136 & 128 & 9.08 & 76.41 & 54.40 & 1986.89 & -408.15 & -81.22 & 14997.52 & 28.53 \\
\hline 300 & 927 & 136 & 123 & 8.75 & 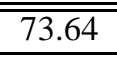 & 52.43 & 1914.72 & -407.72 & -81.48 & 1425.52 & 3.75 \\
\hline
\end{tabular}

(a) The number of trees in the forest is calculated just after the trees are planted, and before the thinning takes place.

(b) All monetary values apart from the discounted net benefit in the last column of the table are expressed as current values. 

a) $\mathrm{t}=0$
b) $t=10$
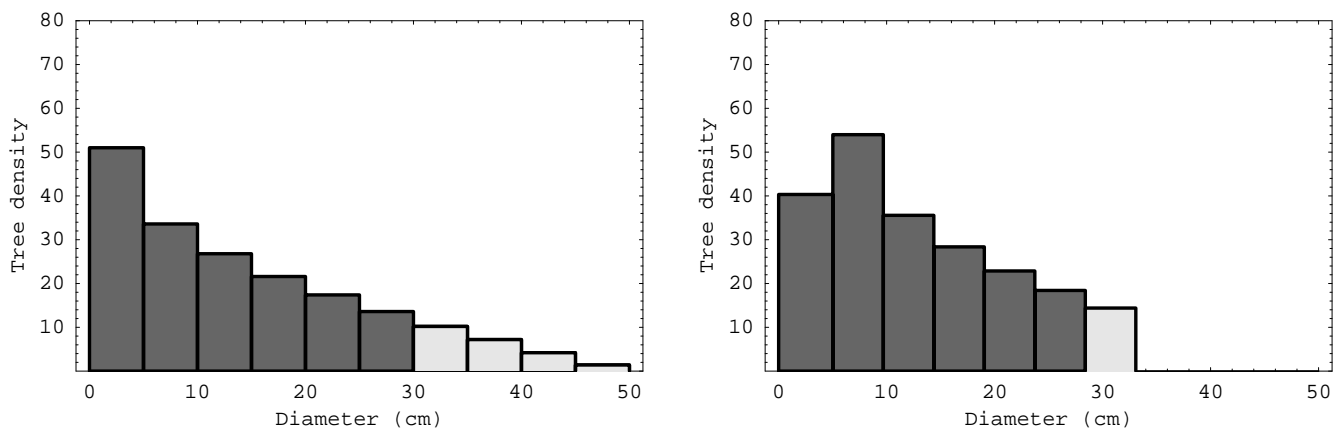

c) $t=50$

d) $\mathrm{t}=100$
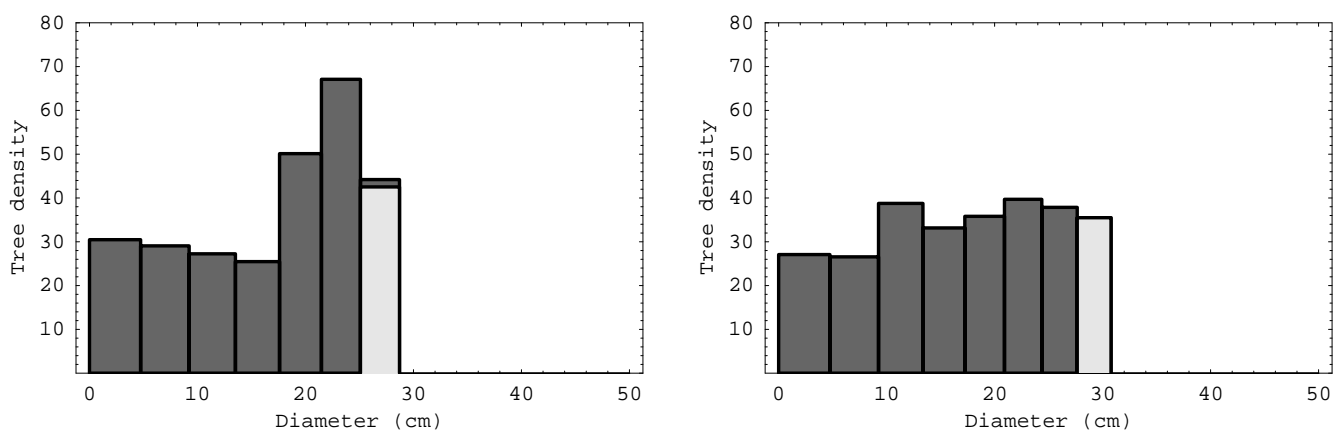

e) $t=200$

f) $t=300$
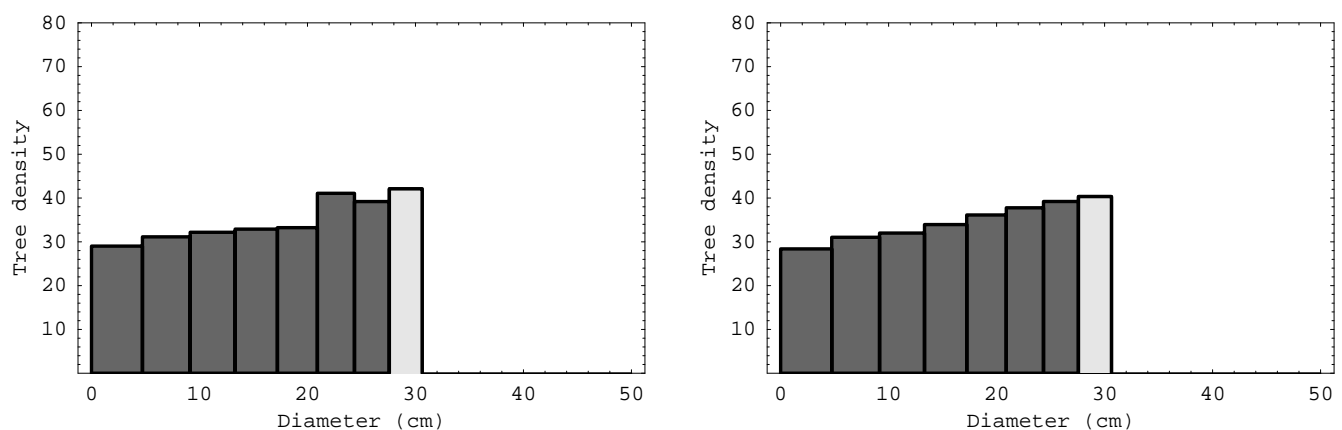

Figure 1: Evolution of the Optimal Diameter Distribution 


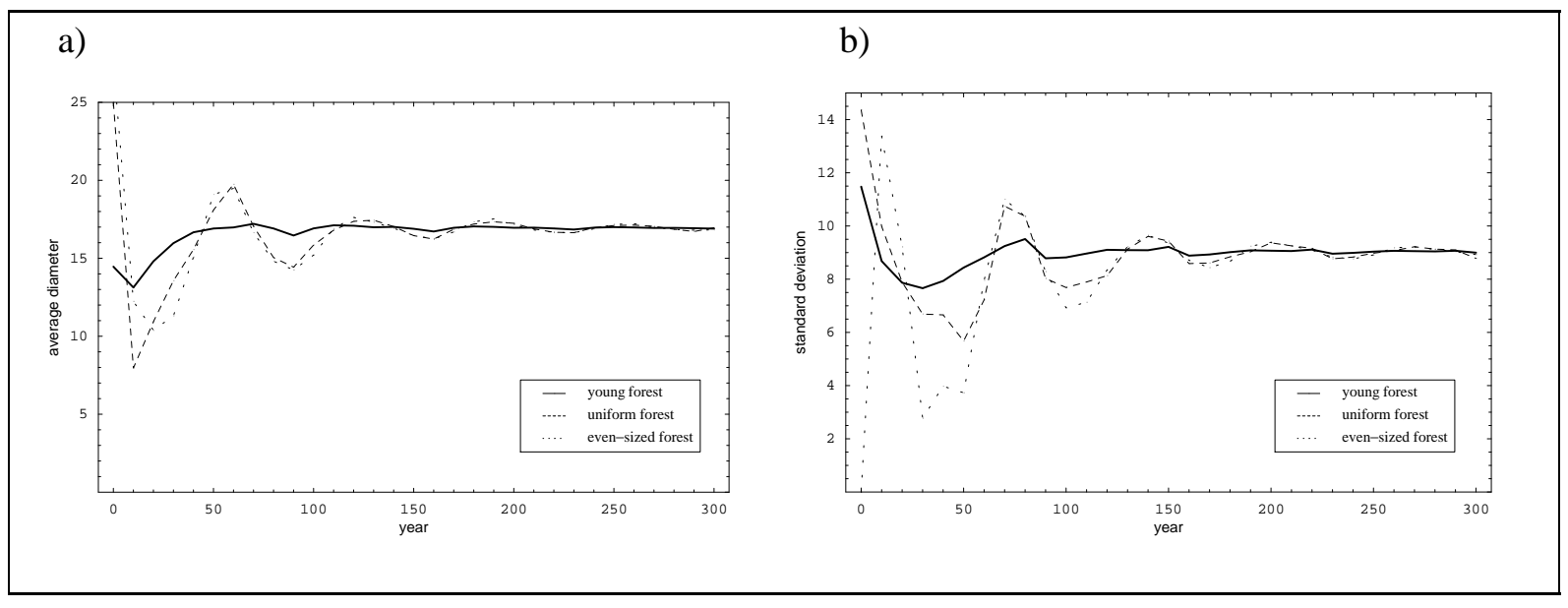

Figure 2: Evolution of the Optimal Diameter Distribution for Different Initial Distributions

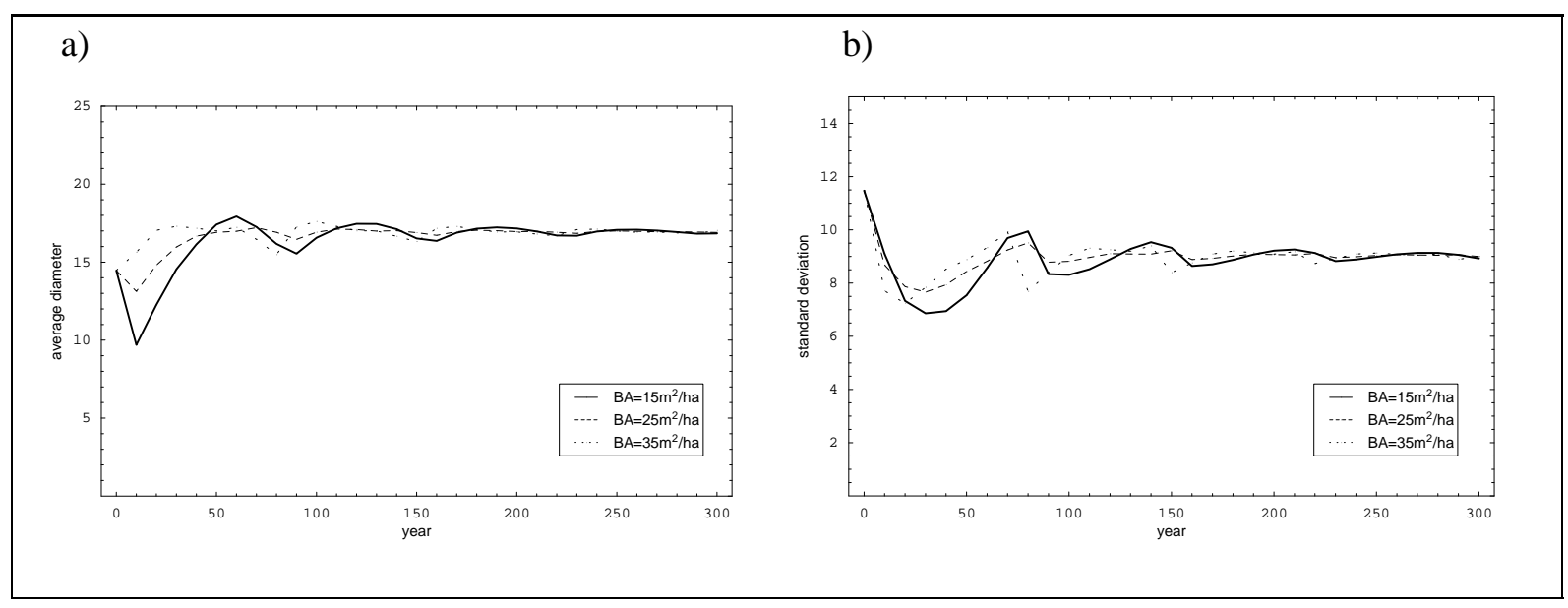

Figure 3: Evolution of the Optimal Diameter Distribution for Different Initial Basal Areas 


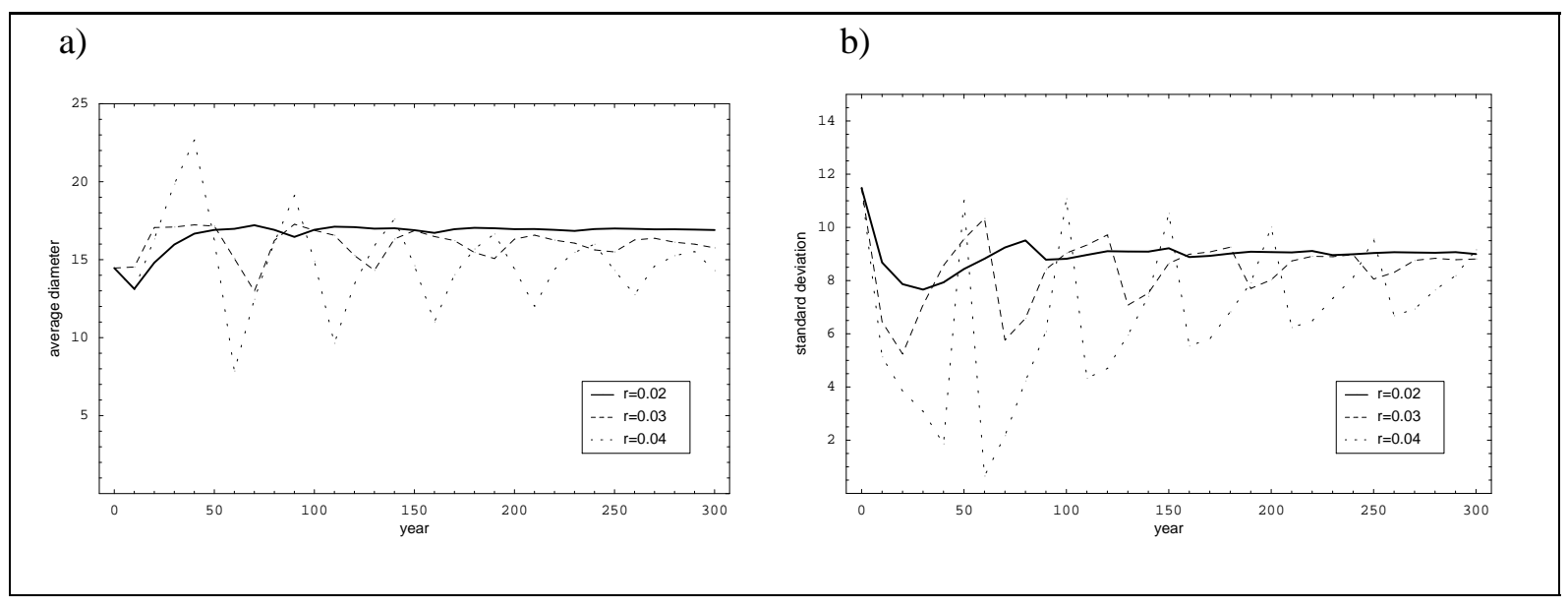

Figure 4: Evolution of the Optimal Diameter Distribution for Different Different Levels of the Discount Rate

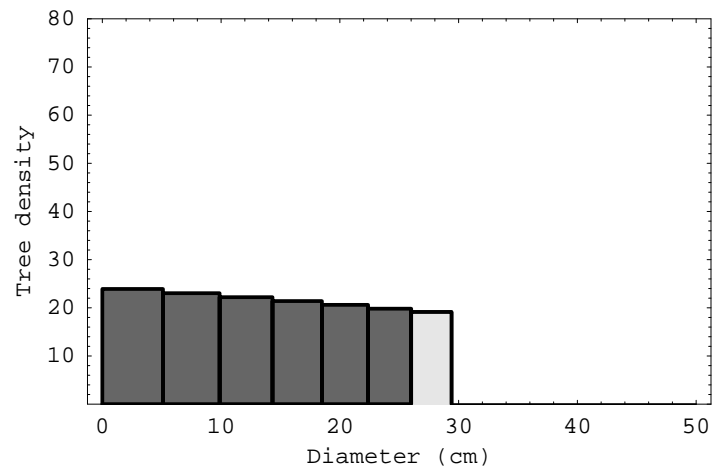

Figure 5: "Long-Run" Diameter Distribution of the Trees Given a Mortality Rate of 0.1 